\title{
Parent Skills Training: Expanding School-Based Services for Adolescent Mothers
}

\author{
Kris Kissman \\ University of Michigan
}

This article reports the results of a collaborative intervention effort between a teen-parent program and a school of social work. Social work faculty and students participated in a program aimed at strengthening parental skills and the utilization of social support among adolescent mothers who were enrolled in a special high school program. The results of this evaluation study point to additional factors, such as empathy training and stress management, which need to be included in a comprehensive service-delivery program for school-age mothers.

The ability of teen mothers to stay in school is influenced by multiple factors and is not limited solely to the availability of child care, housing, food, clothing, and other basic needs. School dropout is a particularly severe problem for this group of adolescents, because only $50 \%$ of teen mothers complete their high school education. School-based services and other teen-parent programs designed to prevent school dropout seem to have a positive impact on school retention among this target population, but they often fail to influence mothers' attitudes or anxiety about the maternal role. These programs are usually targeted toward academic training, and they generally offer limited services to help adolescents cope with their new parental roles, so that they can continue their education (Adler, Bates, \& Merdinger, 1985).

Parent skills training may, at first glance, seem unrelated to school retention, but such skills have been found to be an important aspect of the overall competence that adolescent mothers must develop to meet the multiple demands of school, child care, and - in some cases - employment (Moore, 1987). Brindis and Jeremy (1988) suggest that the effectiveness of teen-parent programs can be increased by introducing a comprehensive range of services, including parental and other skills training required for successful coping with day-to-day demands of the new parental role. Further, an

Author's Note: Correspondence may be addressed to Kris Kissman, School of Social Work, University of Michigan, Ann Arbor, MI 48109.

Research on Social Work Practice, Vol. 2 No. 2, April 1992 161-171

O 1992 Sage Publications, Inc. 
evaluation of the outcome effectiveness of such services can be designed as an integral part of the intervention component (Powers, Meenaghan, \& Toomey, 1985).

In this article, a description of the collaboration of a continuing educational program for teen mothers and an action research project funded and operated under the auspices of a graduate social work program is presented. First, this collaboration led to an increase in the number of services offered to the adolescent parents who were in the process of completing high school requirements. Second, the project provided preliminary data regarding the intervention outcome. Third, a field training opportunity for graduate social work students was developed. The students were exposed to the process of evaluation and assessment as an integral part of their practice experience.

The major features of action research involve an intervention component that is then evaluated for outcome effectiveness (Israel, Schurman, \& House, 1986). Action research is a joint effort between the researcher and, in this case, the teen-parent school in which the research was conducted. The first step was then to utilize the expertise of the school personnel in the assessment of needs and to secure their collaboration and participation throughout the project (Kennis, 1983; Peters \& Robinson, 1984).

The staff and school administration were involved in problem identification and implementation of the intervention plan. The specific steps in this process included (a) identifying additional service needs of the adolescent school population, (b) determining mutual benefits and common goals of the action research project and the school, and (c) assessing the feasibility of a collaborative and participatory joint venture between the two programs.

The school's services were primarily aimed at improving the academic skills of adolescent mothers and at providing referrals to appropriate community agencies to meet the basic needs of the adolescent and her child. The joint assessment of needs resulted in the identification of training needs in the area of skills in coping with the new maternal role. Parental skills training and skills in utilizing social support systems to the fullest extent possible were seen as particularly relevant to the overall goal of enhancing competence among the young mothers.

The intervention component of the project was based on assessment of these needs and on prior research indicating that parental training enhances affectionate responding of young parents and promotes responsive as opposed to punitive parental behaviors (Campbell, Lutzker, \& Cuvo, 1982; Lutzker, Wesch, \& Rice, 1984). A relatively positive parent-child interactional pattern may reduce the stress associated with the parental role by creating less conflictual relationships. Research evidence also suggests that 
teaching parenting skills and other coping strategies to adolescent mothers reduces stress in the parenting role (Rosenberg \& Reppucci, 1985).

The second component of the intervention, strengthening support utilization, was deemed important, because supportive networks can be very responsive in providing some of young mothers' needs in the area of respite child care and other task support, as well as financial resources and emotional support. Teaching young mothers social skills, such as when and how to ask for help, can lead to increases in support utilization (Kissman \& Shapiro, 1990).

Social support is defined by Sarason and Sarason (1982) as "help available to an individual in difficult and stress-arousing situations." The strength of interpersonal relationships is positively related to the effective utilization of such support (Gottlieb, 1985). Recognizing the need for and planning when and how to ask for help, however, involves skills that the adolescent may not have fully developed (Elkind \& Bowen, 1979). Although the intervention was not specifically aimed at enhancing well-being among the group participants in the area of general satisfaction with life, it was hypothesized that the program would indirectly affect well-being. This expectation was based on the association between parental adjustment and well-being. Specifically, psychological well-being has been found to be positively related to maternal adjustment (Colletta, 1983). The transition to parenthood for the adolescent mother seems to require even more significant readjustments in life-style that often strain emotional well-being than is the case for her older counterpart (Thompson, 1986). Early intervention to enhance parental adjustment and well-being is therefore indicated, and the project plans included a measure of general well-being among the adolescent mothers before and after intervention.

The three hypotheses investigated in this study were as follows:

1. Adolescents assigned to group interventions will demonstrate greater increases in social support than adolescents not receiving treatment.

2. Adolescents assigned to group interventions will evidence greater improvements in parental attitudes than adolescents not receiving treatment.

3. Adolescents assigned to group interventions will score higher, on average, on a measure of general well-being than those not participating in group interventions.

The objectives of the project's service components were seen as complementary to services offered by the teen-parent program in the areas of academic skills training and case management. The proposed interventions, hypothesized to enhance parental skills, to encourage the utilization of 
support, and to promote the adolescents' general well-being, were congruent with the teen-parent school's mission of enhancing competence among the young mothers.

The cooperation of the school staff was an essential step in securing release time from classes for students who would attend the group sessions that were planned for intervention. Ongoing collaboration and participation on the part of the school administration and staff were secured through the establishment of a circular feedback system. This ongoing dialogue involved reciprocal and periodic feedback about the overall process of the weekly group sessions.

In order to accomplish this aim, the project director gave monthly reports to the school during regularly scheduled staff meetings regarding the progress being made in groups. The school staff and administrators were asked to provide input about their reactions to and suggestions for modification of the group intervention program. To protect the confidentiality of group participants, emphasis was placed on discussing the group unit as a whole and not individual cases.

\section{METHOD AND PROCEDURES}

\section{Clients}

Twenty-five group participants were selected randomly from the total teen-mother school population of 119 students, with the balance serving as a control group. The demographic factors describing the student population included a mean and median age of 16, ranging from 13 to 18 years of age. Educational level was 10 years of schooling, on the average, with a minimum of 8 and a maximum of 11 grade levels completed. A majority (60\%) of the children born to these school-aged mothers were 6 months of age or younger. Most (91\%) of the mothers were African-American, 5\% were White, and 4\% belonged to other racial categories. The percentage of the students who lived at home was $78 \%$; $15 \%$ lived in residential settings; and $7 \%$ lived with friends, partners, or members of their extended family. The median income reported was $\$ 233$ per month in benefits from Aid to Families with Dependent Children or from earned wages.

The sample was divided into two treatment groups that received identical services provided by two graduate students for the duration of one academic year. The intervention program consisted of weekly $1 \frac{1}{2}$-hour group work sessions. A procedure for contracting with the participants for attendance at 
the weekly sessions was initiated in the beginning of the project period. Additionally, group members were encouraged to participate in "their" group. The establishment of group norms that granted ownership of the group to its participants resulted in an average attendance rate of $75 \%$, which is higher than average school attendance in general.

\section{Social Work Intervention Program}

The intervention program was a cognitive/behavioral approach that had been found to be effective in strengthening adolescent parenting skills (Azar \& Twentyman, 1986). The structured and interactive method used in the sessions stressed child management skills, including the consequences of attending to and reinforcing desired behavior in children, positive interactions between parent and child through planned activities, and young children's needs for nurturance and stimulation.

Some commercially available materials were utilized to demonstrate and promote positive interactions between mother and child. A portion of Mulvey and Vellenoweth's (1982) handbook was used to demonstrate ways to communicate acceptance and encouragement to children by lavish use of positive "do" statements, ways to relate to children without yelling or spanking, the impact of "poison words" on children, and mother's role in building good self-image.

Providing accurate information on child development was seen as an integral part of the parental skills training program. Knowledge about developmental milestones helped the teens set realistic expectations about their children's abilities. Discussions about the various sources of infant crying, temper tantrums, and other noncompliant behavior among toddlers resulted in greater empathy on the part of the teen mother for the needs of her child as opposed to her own needs. This understanding in turn led to exploration of alternatives to punishment, such as taking time out when the interaction between the mother and child became conflictual; giving the toddler some choices; using clear, concise commands; and formulating workable rules.

Throughout the group sessions it became increasingly evident that many of the adolescents at times needed respite child care and emotional and financial help. Strengthening support utilization became a part of the group intervention and involved role playing assertive interactions; skills in identifying, planning, and asking for what one needs; negotiating exchange of services, such as babysitting; resolving conflict by use of "I messages"; and expressing appreciation for support received. 


\section{Outcome Measures}

The four-page questionnaire administered to participants both prior to and after the intervention included measures of parental attitude toward child rearing, support utilization, and general well-being. All of the pregnant and parenting teens in attendance responded to the items contained in the selfadministered instrument.

Parental attitude was measured by Segal's (1985) 24-item Likert-type scale. The instrument is designed to assess the parental role as primarily that of a disciplinarian as opposed to teaching developmental skills to children. The item content includes whether children should be allowed to question the authority of their parents and the importance of providing learning experiences for children at an early age. The higher the score on the scale, the less authoritative and the more "child-centered" the respondent. The interitem reliability, indicated by an alpha coefficient of the measure, was a low .57. Because of the relatively low degree of reliability and, therefore, validity of the scale, the results must be interpreted with caution.

Support from family members, the child's father, peers, neighbors, and friends was assessed by items reflecting the respondent's satisfaction with financial aid, help with babysitting, and emotional support from these sources. The five-item Likert-type items were computed into a scale, similar to the measure reported by LaRocco, House, and French (1980). The alpha coefficient for this measure was a moderate .67 .

Well-being was measured by Diener, Emmons, Larsen, and Griffin's (1984) five-item Likert-type scale indicating the condition of life as excellent, ideal, and satisfactory. The scale has high temporal reliability, and it correlates from moderately to highly with other subjective well-being scales. The alpha coefficient for this measure was moderate at .72 .

\section{RESULTS}

Table 1 depicts the pre- and posttest assessments of the three-outcomemeasures when the clients receiving social group work services were compared with the remainder of the school's teenage mothers who did not receive this program, in effect, a no-treatment control group. As expected, the pretest scores between the treatment and control groups reflect no significant differences in the average scores on the measures of parental adjustment or social support. The treatment group scored significantly lower, however, on the well-being scale prior to intervention at the beginning of the program. 
TABLE 1: Pre- and Posttreatment Intervention Scores for the Experimental and Control Groups (Total $N=119$ )

\begin{tabular}{|c|c|c|c|c|c|c|c|}
\hline \multirow[b]{3}{*}{ Outcome Measure } & \multicolumn{6}{|c|}{ Group } & \multirow[b]{3}{*}{$t$} \\
\hline & \multicolumn{3}{|c|}{ Treatment } & \multicolumn{3}{|c|}{ Control } & \\
\hline & $\mathbf{N}$ & Mean & (SD) & $\mathbf{N}$ & Mean & (SD) & \\
\hline \multicolumn{8}{|l|}{ Support } \\
\hline Pretest & 19 & 13.4 & (2.8) & 62 & 13.9 & $(4.5)$ & -0.5 \\
\hline Posttest & 25 & 20.8 & (5.3) & 94 & 17.5 & $(8.7)$ & $2.7^{\star}$ \\
\hline \multicolumn{8}{|l|}{ Parental attitude } \\
\hline Pretest & 25 & 34.3 & (5.9) & 48 & 35.4 & $(4.0)$ & -0.9 \\
\hline Posttest & 25 & 39.4 & (4.7) & 49 & 35.0 & $(4.2)$ & $4.0 *$ \\
\hline \multicolumn{8}{|l|}{ Well-being } \\
\hline Pretest & 25 & 10.6 & (2.2) & 85 & 12.3 & $(2.9)$ & $-3.4^{*}$ \\
\hline Posttest & 25 & 13.4 & (2.8) & 88 & 12.3 & $(2.6)$ & 1.8 \\
\hline
\end{tabular}

NOTE: Not all teenage mothers were available for pretests and posttests.

${ }^{\star} p<.05 ;{ }^{*} p<.01$.

When the two groups were compared after the intervention, the treatment group showed significant improvements in both social support utilization and parental attitude. The control group did not score significantly higher on the well-being measure, pretest versus posttest, but the gain scores for the treatment group did demonstrate statistically significant improvements.

\section{DISCUSSION}

The results of this pretest-posttest, no-treatment control group design fulfilled the teen-mother school's requirement for outcome results presented in a way that was useful to the school's overall evaluation efforts. The specific parental training project described in this report was not designed as a comprehensive service package for adolescent mothers but, rather, as a first step in an ongoing assessment of intervention needs and evaluation of service effectiveness.

During the process of conducting and evaluating the program the social work students acquired knowledge and skills in facilitating group sessions, and they strove to achieve a subtle balance between providing a semistructured group work format and enabling participants to set their own agenda to some degree. Students also strengthened their interpersonal skills in the school setting, where they had to develop working relationships with 
staff and administrators as well as to demonstrate competence in making a contribution to the overall teen-parent school mission.

Consistent with the aim of action research, the project's findings were utilized to plan future intervention and evaluation components. The results of this study were used to develop federal grant proposals to continue this project, to refine both the intervention and assessment components, and to collect follow-up data of the long-term effects of the program.

In collaboration with the school staff and administrators and based on the outcome evaluations of the pilot program, future assessments will include the following additions and revisions to the intervention and evaluation components of the action research project:

1. The intervention needs to target stress reduction in the form of relaxation exercises and other methods to cope with day-to-day demands of multiple roles. Although parental skills training and support utilization may serve to reduce stress level, interventions that more directly target stress are important because adolescent parenting is associated with high levels of stress that often lead to impatient and intolerant parental behavior.

2. Social skills training did have a significant impact at least on the participants' perception of support utilization. Home visits designed to work with the total family system, including the father of the child, would provide the means for observation of family interactions that promote an increase in support utilization. Home-based interventions are labor intensive, but the feasibility of incorporating even limited home-based services will be explored.

The evaluative component of the program can be expanded to assess various factors predicting a relatively positive parental attitude and behavior toward children. Future plans for testing a causal model include assessing demographic factors, levels of empathy, and knowledge of child development as potential predictors of positive parenting, based on the rationale that parental effectiveness is a multidimensional construct, comprising various measures of attitudes, support, and behavioral interactions. The results of a multiple regression analysis assessing the proportion of variance in parental behavior accounted for by attitude, support network utilization, and other factors may provide important means toward tailoring interventions in the most effective ways. Empathy training would need to be a part of the intervention component, for example, if parental empathy was found to predict positive parental attitude and behavior significantly. Although empathy was not directly measured in the pilot study, our clinical impression was that parental training seemed to increase empathy among the group participants.

Statistical testing of the correlations between the various factors associated with positive parenting can strengthen our conceptualizations about the 
multiple dimensions of parent-child interaction behavior. The potential for testing such conceptual models using reliable and valid measures and the results of this study point to the need for some additional refinements in future studies, as follows.

The measure of psychological well-being needs to reflect levels of worry, tension, and so forth more closely than did the general well-being measure used in the pilot study. The measure of parental distress developed by Milner (1986) will be utilized in future evaluations to assess level of stress. This instrument assesses feelings of frustration, sadness, loneliness, depression, worry, fear, confusion, rejection, and anger. The scale shows an internal consistency level in the middle .90 s across a variety of groups.

An instrument with a higher interitem reliability than the parental attitude measure utilized in the pilot study will be selected. The Parental Acceptance and Rejection Questionnaire scale, developed by Rohner (1975) and reported by Colletta (1983) as having an interitem reliability of .90 as well as good concurrent and discriminant validity, will be used in subsequent assessments. The scale measures maternal attitudes in areas of warmth or affection, aggression or hostility, and neglect.

Although attitudinal measures are an important part of the parent-child interaction pattern (Segal, 1985), observations of mother-child interactions are needed to assess overall parental behavior. Direct observations of parentchild interactional behaviors will be implemented and correlated with the attitudinal measures. The HOME Inventory developed by Caldwell and Bradley (1984) can be modified to the school setting and includes observations of positive and negative interactions between mother and child. This measure assesses specific areas of parental responsiveness, such as (a) emotional and verbal responsiveness, (b) avoidance of restriction and punishment, (c) maternal involvement with the child, and (d) opportunities for varieties in daily situations. These observations can be made in the school setting where children accompany their mothers. Ample time (at least one hour) will need to be allocated for these observations.

Another modification in future studies includes prompting respondents to complete all the items on the questionnaires. The control group in the current study failed to respond to some of the items, particularly on the parental attitude measure, and resulting missing values created a limitation to the study findings.

A final note about the negative effects of combining the needs of the school and the research project is that the experimental design of the study does limit the feasibility of selecting those individuals with the lowest scores on the positive parenting, behavioral interaction, and support utilization measures. 
Although the predictive validity of these scales measuring these variables has not been established and the measures should be utilized with caution in targeting the most at-risk subgroup of adolescents for intervention, the random selection procedure does limit the selection of treatment participants based on needs. We look forward to additional and better designed studies in this area.

\section{REFERENCES}

Adler, E. S., Bates, M., \& Merdinger, J. M. (1985). Educational policies and programs for teenage parents and pregnant teenagers. Family Relations, 34, 183-187.

Azar, S., \& Twentyman, C. (1986). Cognitive-behavioral perspectives on the assessment and treatment of child abuse. Advances in cognitive-behavioral research and therapy (pp. 237. 269). New York: Academic Press.

Brindis, C. D., \& Jeremy, R. (1988). Adolescent pregnancy and poverty in California: A strategic plan for action. San Francisco: University of San Francisco.

Caldwell, B., \& Bradley, R. H. (1984). Home observation for measurement of the environment (rev. ed.). Little Rock: University of Arkansas.

Campbell, R. V., Lutzker, J. R., \& Cuvo, A. J. (1982, May). Comparative study of affection in low social economic families across status of abuse, neglect and non-abuse neglect. Paper presented at the Eighth Annual Convention of the Association for Behavioral Analysis, Milwaukee, WI.

Colletta, N. D. (1983). At risk for depression: A study of young mothers. Journal of Genetic Psychology, 142, 301-310.

Diener, E., Emmons, R. A., Larsen, R. J., \& Griffin, S. (1985). The satisfaction with life scale. Journal of Personality Assessment, 49, 71-75.

Elkind, D., \& Bowen, R. (1979). Imaginary audience behavior in children and adolescents. Developmental Psychology, 15, 38-44.

Gottlieb, B. H. (1985). Combining lay and professional resources to promote human welfare: Prospects and tensions. In J. A. Yoder, J.N.L. Jonker, \& R.H.B. Leaper (Eds.), Support networks in a caring community. Boston: Martinus Nijhoff.

Israel, B. A., Schurman, S. J., \& House, J. S. (1986). An action research approach tooccupational stress and health. Unpublished manuscript, University of Michigan, School of Public Health.

Kennis, S. (1983). Action research. In D. S. Anderson \& C. Blaker (Eds.), Youth, transition and social research. Canberra: Australian National University Press.

Kissman, K., \& Shapiro, J. (1990). The composites of social support and well-being among adolescent mothers. International Journal of Adolescence and Youth, 2, 165-174.

LaRocco, J., House, H. S., \& French, J.R.D. (1980). Social support, occupational stress and health. Journal of Health and Social Behavior, 21, 202-218.

Lutzker, J. R., Wesch, D., \& Rice, J. J. (1984). A review of "Project 12-Ways": An ecobehavioral approach in the treatment and prevention of child abuse and neglect. Advances in Behaviour Research and Therapy, 6, 63-73.

Milner, J. S. (1986). The Child Abuse Potential Inventory (2nd ed.). Webster, NC: Psytec.

Moore, K. A. (1987). Facts at a glance. Washington, DC: Child Trends.

Mulvey, L., \& Vellenoweth, C. (1982). Handbook for parent education for low income families. (Available from the authors at 3729 Tedrich Blvd., Fairfax, VA 22031) 
Peters, M., \& Robinson, V. (1984). The origins and status of action research. Journal of Applied Behavioral Science, 20, 113-124.

Powers, G. T., Meenaghan, T. M., \& Toomey, B. G. (1985). Practice focused research: Integrating human service practice and research. Englewood Cliffs, NJ: Prentice-Hall.

Rohner, R. P. (1975). They love me, they love me not: A worldwide study of the effects of parental acceptance and rejection. New York: HRAF Press.

Rosenberg, M. S., \& Reppucci, N. D. (1985). Primary prevention of child abuse. Journal of Consulting and Clinical Psychology, 53, 576-585.

Sarason, 1. G., \& Sarason, B. R. (1982). Concomitants of social support, attitudes, personality characteristics and life experiences. Journal of Personality, 50, 331-345.

Segal, M. (1985). A study of maternal beliefs and values within the context of an intervention program. In I. Sigel (Ed.), Parental belief systems. Hillsdale, NJ: Lawrence Erlbaum.

Thompson, M. S. (1986). The influence of supportive relationships on the psychological wellbeing of teenage mothers. Social Forces, 64, 1006-1024. 